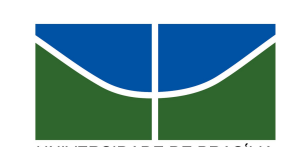

UNIVERSIDADE DE BRASÍLIA

Centro de Excelência em Turismo

Pós-graduação Lato Sensu

Curso de Especialização em Gastronomia e Saúde

\title{
Determinação do Fator de Correção das Hortaliças Folhosas do CEASA de Brasília - DF
}

\author{
Aline Guimarães Lemos
}

Orientadora: Prof. ${ }^{a}$ Dr$^{\mathrm{a}}$. Rita de Cássia Akutsu 


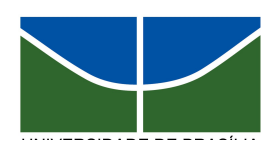

UNIVERSIDADE DE BRASÍLIA

Centro de Excelência em Turismo

Pós-graduação Lato Sensu

Curso de Especialização em Gastronomia e Saúde

\title{
Determinação do Fator de Correção das Hortaliças Folhosas do CEASA de Brasília - DF
}

\begin{abstract}
Aline Guimarães Lemos
Orientadora: Prof. ${ }^{a}$ Dr$^{\mathrm{a}}$. Rita de Cássia Akutsu

Monografia apresentada ao Centro de Excelência em Turismo - CET, da Universidade de Brasília - UnB, como requisito parcial à obtenção do grau de Especialista em Gastronomia e Saúde.
\end{abstract}

Brasília - 2008 


\section{UNIVERSIDADE DE BRASÍLIA}

Centro de Excelência em Turismo

Pós-graduação Lato Sensu

Curso de Especialização em Gastronomia e Saúde

\section{Aline Guimarães Lemos}

Aprovado por:

Orientador: Prof. ${ }^{\mathrm{a}} \mathrm{Dr}^{\mathrm{a}}$. Rita de Cássia Akutsu

Prof. ${ }^{a}$ Dr $^{\mathbf{a}}$. Raquel Braz Assunção Botelho

Prof. ${ }^{a}$ Dr $^{a}$. Karin Eleonora Savio de Oliveira

Brasília, 22 de julho de 2008. 


\section{DEDICATÓRIA}

Dedico este trabalho à Professora Doutora Rita de Cássia Akutsu e à Professora Doutora Raquel Assunção Botelho que contribuíram para que eu pudesse realizar esta pesquisa. Dedico a Deus, por abençoar cada passo meu. Dedico a meu marido Jader por estar ao meu lado todos os dias, dando forças para continuar esta batalha. 


\section{RESUMO}

O Brasil tem índices elevados de desperdício alimentício, fato que afeta a economia e acentua problemas sociais. O planejamento inadequado do processamento de alimentos, da pós-colheita ao consumo, é um dos canais do desperdício. As hortaliças, por passarem por diversas práticas higienizadoras e por serem submetidas operações culinárias de subdivisão e cocção, têm sua durabilidade relacionada a uma série de fatores fisiológicos, mecânicos e ambientais. A deterioração das hortaliças é um processo irreversível e inevitável, sendo um dos grupos de alimentos mais desperdiçado. Para buscar minimizar perdas, a determinação do Fator de Correção de hortaliças, cuja fórmula é estabelecida pela relação do peso bruto (alimento como é adquirido) e com o peso líquido (alimento depois de limpo e processado) é essencial, pois, por meio dele, pode-se avaliar mais precisamente o grau de desperdício e quais fatores intervêm em perdas. Este trabalho consiste da determinação de Fator de Correção das seguintes hortaliças folhosas: Alface Americana, Alface Crespa, Alface Lisa, Alface Roxa, Acelga, Almeirão, Agrião, Chicória, Couve manteiga, Escarola, Espinafre, Mostarda, Repolho Branco, Repolho Roxo e Rúcula.

Com o objetivo de detectar se existe influência dos meses de coleta sobre os fatores de correção parcial (FC 1) e final (FC 2) utilizou-se as seguintes ferramentas estatísticas: Análise de Variância (ANOVA) - quando os fatores de correção ou seu logaritmo apresentaram normalidade e (i) Kruskal-Wallis - quando os fatores de correção ou seu logaritmo não apresentaram normalidade. Uma vez encontrada diferenças significativas entre os meses de coleta aplicou-se o teste de Tuckey afim de detectar os meses que diferem entre si. Em todos os testes considerou-se um nível de $5 \%$ de significância estatística.

Termos de indexação: Fator de correção. Hortaliças folhosas. Desperdício. 


\section{LISTA DE TABELAS}

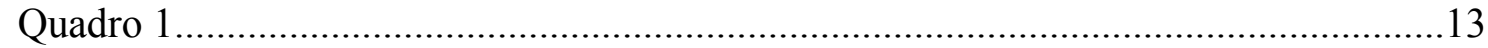

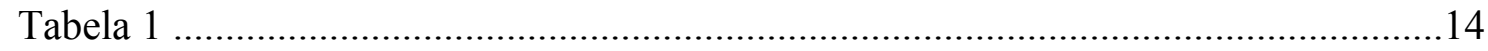

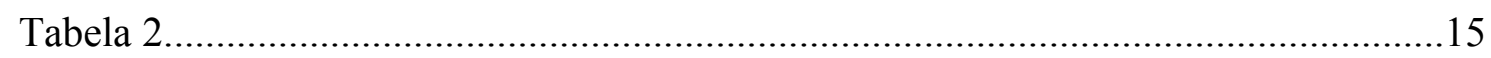

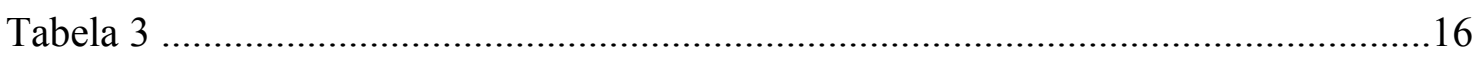

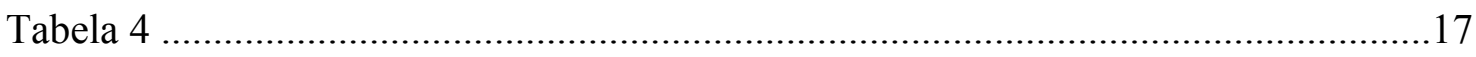

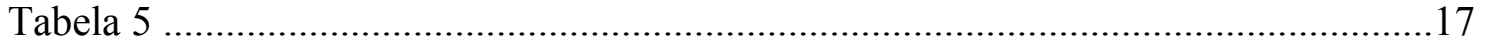




\section{SUMÁRIO}

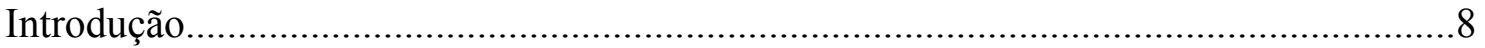

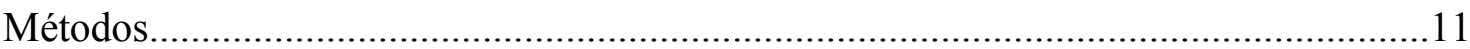

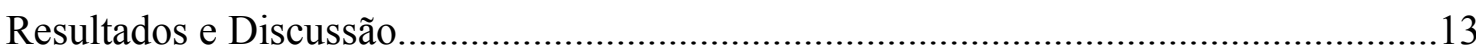

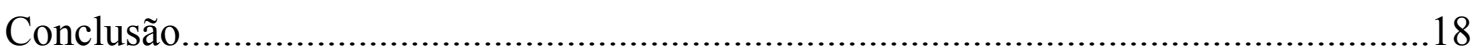

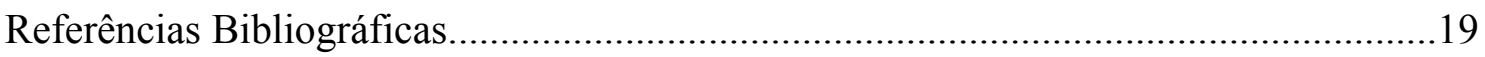




\section{INTRODUÇÃO}

Os vegetais foram os primeiros alimentos do homem. A palavra vegetal originou-se do verbo em latim vegere, que significa revigorar. As hortaliças compõem este grupo, são geralmente cultivadas em hortas e compreendem as partes comíveis das plantas: raízes tuberosas, tubérculos, caules, folhas, flores, frutos e sementes. Popularmente são conhecidas como verduras e legumes e têm um papel importante na mesa do brasileiro por serem fontes de fibras, vitaminas e minerais (ARAÚJO et al., 2007; TEICHMANN, 2000).

Em virtude da diversidade de conceitos acerca da nomenclatura das partes comíveis, este estudo adota as seguintes definições de hortaliças: segundo a ANVISA (1978), "Hortaliça é a planta herbácea da qual uma ou mais partes são utilizadas como alimento na sua forma natural" ou o conceito "Hortaliças, diferentes partes da planta consumidas frescas como saladas ou preparadas de diferentes maneiras" (PIF, 2006). Assim, o termo hortaliça designa de forma genérica as plantas herbáceas empregadas na alimentação humana.

Segundo Borges (1991), o Brasil é um dos países latinos mais férteis para o cultivo do desperdício. Aqui, recursos naturais, financeiros, de oportunidades e até de alimentos, muitas vezes não são aproveitados, sem possibilidade de retorno. O desperdício está agrupado à cultura brasileira, portanto, é difícil de ser alterado. Ele afeta a produção do país, resultando em sintomas perniciosos para toda a sociedade. Apenas o desperdício de alimentos gera um prejuízo equivale a 1,4\% do PIB nacional (PERRONE, 2004). No entanto, Paneta (2005) mostra um contingente crescente de consumidores de alimentos que passaram a questionar os processos produtivos da indústria alimentícia. A preocupação com a própria saúde deixa de existir isoladamente e soma-se à preocupação com a manutenção do meio ambiente.

Para que as hortaliças não sejam desperdiçadas, o cuidado deve começar no campo, no processo da colheita, devendo englobar todas as etapas, da pós-colheita ao consumo. As hortaliças destinadas ao consumo in natura alcançam sua qualidade máxima no momento da colheita, podendo ser preservadas somente até um determinado limite. A qualidade desses produtos depende de uma série de fatores fisiológicos, mecânicos e ambientais. Portanto, a deterioração das hortaliças é um processo irreversível e inevitável podendo no máximo ser retardado. 
A pós-colheita tem papel essencial no atendimento dos anseios dos consumidores, pois é nesta etapa que acontecem os processos de classificação, embalagem, manuseio e transporte que devem ser adequados à cadeia produtiva. A nãoutilização desses processos e algumas práticas adotadas pelos produtores, como a colheita precoce, na tentativa de que o alimento resista ao transporte, acabam trazendo uma depreciação na qualidade do produto (IEA, 2008).

As perdas das hortaliças, desde o momento da colheita até a mesa do consumidor, são da ordem de 35\%. Contudo, algumas tecnologias pós-colheita podem ser aplicadas para diminuir as perdas e manter a qualidade do produto, como por exemplo, o uso de embalagens que respeitem as características do vegetal, a paletização da carga, a utilização de câmaras frias, o transporte e a armazenagem apropriados (BRASIL, 1993).

As condições que podem influir na característica nutritiva e organoléptica dos alimentos de origem vegetal são ecológicas, relacionadas com a época, com o estado de maturação e com o processo de colheita (EVANGELISTA, 1992). Em virtude das técnicas de produção, processamento e armazenamento, o alimento também pode sofrer alterações nutritivas. Contaminações químicas das hortaliças ocorrem por meio do uso de pesticidas e quimoterapêuticos ou por componentes de embalagens nocivos.

Segundo o CEAGESP (BRASIL, 2008), da pós-colheita até o consumo, o desperdício ocorre, variando de acordo com o processo sofrido pelo o alimento. Logo após a apanha, muitas hortaliças são descartadas totalmente ou parcialmente devido a seu grau de maturação, defeitos que tornem indesejáveis sua aceitação no mercado ou graças a deformações estéticas em folhas ou amassos em frutos. Se o produto for lavado em seu processamento, ele deve ser seco, pois, caso fique úmido ou molhado, poderá causar apodrecimento e contaminação, e conseqüentemente, inviabilidade de consumo. Além disso, freqüentemente, a tolerância de temperatura e umidade não é respeitada nos locais de estocagem. $\mathrm{O}$ manejo imoderado dos alimentos feito durante o transporte ou por meio dos utensílios utilizados nos postos de venda também põe os produtos a perder.

A perda de alimentos é uma questão importantíssima para a gestão de uma Unidade de Alimentação e Nutrição (UAN) e esta designa um ambiente que desenvolve atividades relacionadas à nutrição, como planejamento e elaboração de refeições equilibradas, nutritivas, salubres e seguras da perspectiva higiênica, pretendendo auxiliar no desenvolvimento de hábitos alimentares saudáveis (LANZILLOTTI et al., 
2004; PROENÇA et al., 2005). A economia, a política, a cultura e a tecnologia estão diretamente ligadas ao processo de desperdício desde a pré-colheita até o consumo. Assim, o desperdício não é apenas um índice técnico a ser observado pelo profissional nutricionista - é também um problema de saúde pública. O ambiente físico, suas instalações e sua relação com condições de higiene adequadas - tanto das instalações e quanto dos manipuladores - devem ser cuidadosamente planejados em vistas a barrar o desperdício. Também a padronização de processos e serviços, por meio da criação de rotinas e procedimentos técnicos operacionais, treinamento da equipe e controle das atividades por meio de análises devem ser levados em consideração para que perdas não ocorram (HIRSCHBRUCH, 1998).

É fundamental um bom planejamento antes de qualquer atividade, pois muitos transtornos podem ser evitados durante sua execução. O planejamento ardiloso, tático e operacional é elemento componente do processo de controle da empresa seguido da avaliação de resultados e decisões corretivas (GOMES; SALAS, 1999). Segundo Akutsu et al. (2005), uma UAN deve visar o progresso dos serviços prestados, através de um planejamento correto, de um conhecimento aprofundado dos processos executados e da disseminação do conceito de alimentação saudável. Para melhor atendermos este planejamento, Akutsu et al. (2005) e Guimarães (2000) citam alguns indicadores que auxiliam este, como por exemplo, a Ficha Técnica de Preparo (FTP), que contém os seguintes indicadores: per capita, fator de correção e cocção, composição centesimal em macro e micronutrientes da preparação, o rendimento e o número de porções da mesma. Tais itens, bem como o cardápio calculado discriminando os ingredientes, o modo de preparo, os equipamentos e os utensílios a serem utilizados, as temperaturas adequadas, e a seqüência exata de preparação, constituem-se indicadores internos da FTP.

O indicador de desperdício chamado de Fator de Correção (FC), é o fator utilizado para determinar a quantidade exata de alimento que será descartado na alimentação e deve ser utilizado ao planejar quantitativamente um cardápio e seus gêneros. Deve-se levar em conta que dependendo do fornecedor e tipo de produto, este fator pode variar muito, sendo assim as perdas sofridas pelos alimentos variam em função de alguns fatores tais como: tipo de alimento, qualidade e grau de amadurecimento (safra), técnicas utilizadas no pré-preparo e habilidade do operador. (CAMARGO; BOTELHO,2005) 
Para a transformação das hortaliças na produção, removem-se, inicialmente, folhas velhas, talos endurecidos, pedaços deteriorados, cascas, etc., que representam uma perda inevitável do peso inicial, podendo representar até $62 \%$, como é o caso do milho verde. (ORNELLAS, 2001).

Sendo assim, com o intuito de aproveitar ao máximo os alimentos, o fator de correção pode contribuir para o alcance deste objetivo, visto que as perdas inevitáveis sofridas pelos alimentos na fase de pré-preparo dos mesmos podem ser minimizadas (ORNELLAS, 2001).

Pereira (1993) realizou um estudo com um total de 18.000 refeições diárias, em cinco meses, as saladas foram as preparações que apresentaram maior desperdício nos pratos dos comensais, principalmente as folhosas. Percebeu-se então uma necessidade de mudanças no cardápio, como inclusão de saladas mistas e compostas no que diz respeito aos cortes feitos nos alimentos, entre outros. Pode-se observar então a importância do profissional nutricionista, no gerenciamento de uma UAN, tendo em reflexão não somente a questão ética, mas também econômica, política e social, já que no Brasil a miséria é considerada como um dos problemas de saúde pública.

Devido ao número elevado de usos sem proveito das hortaliças na alimentação e devido à sua importância na saúde humana, considera-se a necessidade de estudos que avaliem o fator de correção para se estipular com precisão o desperdício ao higienizar, manipular e selecionar esses alimentos. O desperdício acentuado das herbáceas demonstra a necessidade da utilização desses indicadores nas UANs, para que assim se possa evitar que quantidades significativas de hortaliças não seja utilizada.

Diante do exposto, este trabalho teve o objetivo de determinar o desperdício, usando o indicador Fator de Correção de hortaliças folhosas distribuídas no CEASA (Central de Abastecimento) de Brasília, Distrito Federal.

\section{MÉTODOS}

Este estudo foi conduzido no CEASA - Central de Abastecimento - Brasília, Distrito Federal, localizado no Setor de Indústria e Abastecimento (SIA) Trecho 10 Lote $\mathrm{n}^{\circ}$ 5. Para a determinação das amostras, foram realizadas três visitas ao local, nos meses de abril, maio e junho (uma visita em cada mês) para aquisição das amostras das hortaliças folhosas disponíveis. 
As hortaliças inventariadas nesta pesquisa foram: Alface Americana, Alface Crespa, Alface Lisa, Alface Roxa, Acelga, Almeirão, Agrião, Chicória, Couve manteiga, Escarola, Espinafre, Mostarda, Repolho Branco, Repolho Roxo e Rúcula.

Foram adquiridas três unidades de venda do CEASA de cada hortaliça, de fornecedores diferentes, com três repetições, perfazendo um total de nove amostras por hortaliças, ou seja, foram adquiridas três amostras de cada hortaliça em abril, três em maio e três em junho.

As pesagens foram realizadas no Laboratório de Técnica Dietética da Universidade de Brasília, Brasília, Distrito Federal. Foi utilizada uma balança da marca Marte ${ }^{\circledR}$ modelo AS 2000 , com capacidade carga máxima de 2000 g e carga mínima de $0,25 \mathrm{~g}$, com precisão de $0,05 \mathrm{~g}$.

Para a determinação do Fator de Correção, foi utilizada a fórmula clássica sugerida por (ARAÚJO et al., 2007), foi determinado então o FC 1 parcial - para a sua obtenção foram retiradas das hortaliças as folhas danificadas, as raízes e os talos centrais que são habitualmente retirados. Foi determinado FC 2 final - para sua obtenção foram retirados das hortaliças somente os talos que não são hábito serem retirados, como por exemplo todos os talos laterais do agrião deixando somente as folhas.

Os resultados dos FCs, foram elaborados a partir de cálculo aritmético da média das nove amostras. Determinou-se a Média Aritmética, Desvio Padrão, Coeficiente de Variação (CV) com o programa Excel das três amostras de cada pesagem e da média final das três pesagens finais.

Para analisar o Coeficiente de Variação - CV, foi utilizado Gomes (2000), interpretado como a variabilidade dos dados em relação à média. Quanto menor o Coeficiente de Variação, mais homogêneo é o conjunto de dados. Os valores de CV utilizados por Gomes são baixo (inferior a 10\%); médio (de 10\% a 20\%); alto (de 20\% a $30 \%$ ) e muito alto (superior a $30 \%$ ).

Para análise estatística foram empregadas análise de variância (ANOVA), quando os fatores de correção ou seu logaritmo apresentaram normalidade e KruskalWallis quando os fatores de correção ou seu logaritmo não apresentaram normalidade.

O teste de Turkey foi utilizado para detectar os meses com diferença de significância estatística quando verificadas diferenças significativas nos pesos das hortaliças de acordo com o mês da coleta da amostra.

Fixou-se, para todos os testes, nível de significância de $5 \%(\mathrm{p}<0,05)$. 


\section{RESULTADOS E DISCUSSÃO}

Para melhor compreensão os resultados serão apresentados na forma de cinco tabelas e um quadro.

O QUADRO 1 contém as informações relevantes de cada hortaliça analisada. Dentre elas o nome científico, as partes retiradas para cálculo do fator de correção, os fatores de correção, o período de safra e a unidade de compra. Essas consistem em informações fundamentais no contexto de uma UAN, uma vez que caracteriza e permite a padronização dos produtos processados pela mesma.

QUADRO 1 - IDENTIFICAÇVO E FATOR DE CORREÇVO DE HORTALIÇAS COMERCIALIZADAS NO CEASA DE BRASÍLIA - DF, 2008

\begin{tabular}{|c|c|c|c|c|c|c|}
\hline Hortaliça & Nome científico & Partes retiradas & $F C 1$ & $F C 2$ & $\begin{array}{l}\text { Unidade } \\
\text { compra }\end{array}$ & Safra \\
\hline $\begin{array}{l}\text { alface } \\
\text { americana }\end{array}$ & Lactuca sativa $L$. & folhas danificadas & 1,36 & $*$ & cabeça & maio a dez \\
\hline alface roxa & Lactuca sativa $L$. & folhas danificadas & 1,4 & * & cabeça & maio a dez \\
\hline alface lisa & Lactuca sativa $L$. & folhas danificadas & 1,34 & * & cabeça & maio a dez \\
\hline alface crespa & Lactuca sativa $L$. & folhas danificadas & 1,41 & * & cabeça & maio a dez \\
\hline acelga & Beta vulgaris cicla & $\begin{array}{l}\text { folhas danificadas, } \\
\text { talo inferior }\end{array}$ & 1,71 & * & cabeça & maio a nov \\
\hline acelga & Beta vulgaris cicla & centro & * & 3,01 & cabeça & maio a nov \\
\hline agrião & $\begin{array}{l}\text { Nasturtium officinale } \\
\text { R. Br. }\end{array}$ & $\begin{array}{l}\text { folhas danificadas, } \\
\text { talo central }\end{array}$ & 2,33 & $*$ & maço & maio a nov \\
\hline agrião & Lepidium virginicum $L$ & talo de cada folha & $*$ & 4,09 & maço & maio a nov \\
\hline almeirão & Cichorium intybus L & folhas danificadas & 1,62 & $*$ & maço & maio a dez \\
\hline couve & $\begin{array}{l}\text { Brassica oleracea } L . \\
\text { var. acephala }\end{array}$ & $\begin{array}{l}\text { folhas danificadas, } \\
\text { talo central }\end{array}$ & 1,6 & $*$ & maço & $\begin{array}{l}\text { jan e jul } \\
\text { a dez }\end{array}$ \\
\hline chicória & Cichorium endivia L. & folhas danificadas & 1,45 & * & maço & jun a dez \\
\hline espinafre & Spinacea oleracea L. & $\begin{array}{l}\text { folhas danificadas, } \\
\text { talo central }\end{array}$ & 1,57 & $*$ & maço & jun a dez \\
\hline espinafre & Spinacea oleracea L. & talo de cada folha & $*$ & 2,05 & maço & jun a dez \\
\hline escarola & $\begin{array}{l}\text { Beta vulgaris } L . \text { var. } \\
\text { cicla }\end{array}$ & folhas danificadas & 1,28 & $*$ & maço & $\begin{array}{l}\text { jan e jun a } \\
\text { set e dez }\end{array}$ \\
\hline mostarda & Sinapis arvensis $L$. & $\begin{array}{l}\text { folhas danificadas, } \\
\text { talo central }\end{array}$ & 1,81 & $*$ & maço & jul a dez \\
\hline repolho branco & $\begin{array}{l}\text { Brassica oleracea } L . \\
\text { var. capitata }\end{array}$ & $\begin{array}{l}\text { folhas danificadas, } \\
\text { centro }\end{array}$ & 1,12 & $*$ & cabeça & $\begin{array}{l}\text { jan e fev e } \\
\text { jul a dez }\end{array}$ \\
\hline repolho roxo & $\begin{array}{l}\text { Brassica oleracea } L . \\
\text { var. capitata }\end{array}$ & $\begin{array}{l}\text { folhas danificadas, } \\
\text { centro }\end{array}$ & 1,12 & $*$ & cabeça & $\begin{array}{l}\text { jan e fev e } \\
\text { jul a dez }\end{array}$ \\
\hline rúcula & Eruca sativa $L$. & $\begin{array}{l}\text { folhas danificadas, } \\
\text { raízes }\end{array}$ & 1,86 & $*$ & maço & $\begin{array}{l}\text { maio e set } \\
\text { a dez }\end{array}$ \\
\hline rúcula & Eruca sativa $L$. & nervuras & $*$ & 3,24 & maço & $\begin{array}{l}\text { maio e set } \\
\text { a dez }\end{array}$ \\
\hline
\end{tabular}

Na TABELA 1, a partir da média do peso em gramas de cada hortaliça, observase a existência de coeficientes de variação elevados devido as importantes diferenças de pesos das nove amostras coletadas. 
A colheita, a pós colheita, o transporte e o armazenamento, e principalmente as diferenças de tamanho do produto de um fornecedor para o outro são fatores de grande influência na qualidade e integridade do produto que passará pelo processo de produção interferindo diretamente no $\mathrm{FC}$ e conseqüentemente ao produto final. Tais características diferem a cada fornecedor, o que possivelmente se reflete na diferença de pesos observada. Verifica-se então a falta de padronização de pesos entre os fornecedores de hortaliças do CEASA - DF.

TABELA 1 - MEDIDAS DE TENDÊNCIA CENTRAL DAS HORTALIÇAS COMERCIALIZADAS NO CEASA DE BRASÍLIA - DF, 2008

\begin{tabular}{l|ccc|ccc|ccc}
\hline \multirow{2}{*}{ Hortaliças } & \multicolumn{3}{|c|}{ Abril } & \multicolumn{3}{c|}{ Maio } & \multicolumn{3}{c}{ Junho } \\
\cline { 2 - 11 } & Média(g) & $\mathrm{DP}(\mathbf{g})$ & $\mathrm{CV} \%$ & Média(g) & $\mathrm{DP}(\mathrm{g})$ & $\mathrm{CV} \%$ & Média(g) & $\mathrm{DP}(\mathrm{g})$ & $\mathbf{C V} \%$ \\
\hline alface americana & 305,08 & 67,36 & 22,08 & 370,80 & 75,76 & 20,43 & 496,44 & 87,76 & 17,68 \\
alface roxa & 204,65 & 73,32 & 35,83 & 207,75 & 85,18 & 41,00 & 138,66 & 12,78 & 9 \\
alface lisa & 208,37 & 21,83 & 10,48 & 261,67 & 35,93 & 13,73 & 313,49 & 58,78 & 18,75 \\
alface crespa & 156,96 & 4,66 & 2,97 & 205,30 & 42,46 & 20,68 & 213,25 & 37,77 & 17,71 \\
acelga & 1223,60 & 443,28 & 36,23 & 1086,42 & 110,67 & 10,19 & 1154,86 & 329,76 & 28,55 \\
agrião & 457,44 & 36,51 & 7,98 & 485,79 & 24,86 & 5,12 & 470,30 & 10,68 & 2,27 \\
almeirão & 272,59 & 93,38 & 34,26 & 266,24 & 33,16 & 12,46 & 242,18 & 53,35 & 22,03 \\
couve & 432,65 & 8,98 & 2,08 & 407,41 & 38,48 & 9,44 & 378,22 & 13,86 & 3,67 \\
chicória & 242,48 & 12,16 & 5,02 & 266,63 & 32,02 & 12,01 & 281,19 & 92,57 & 32,92 \\
espinafre & 410,59 & 124,85 & 30,41 & 590,78 & 57,75 & 9,77 & 706,86 & 137,45 & 19,44 \\
escarola & 241,07 & 33,42 & 13,86 & 234,42 & 33,92 & 14,47 & 254,42 & 58,81 & 23,12 \\
mostarda & 357,67 & 54,26 & 15,17 & 382,57 & 157,90 & 41,27 & 496,13 & 180,15 & 36,31 \\
repolho branco & 981,69 & 154,04 & 15,69 & 1087,64 & 93,72 & 8,62 & 1400,15 & 225,85 & 16,13 \\
repolho roxo & 1114,71 & 225,74 & 20,25 & 1217,01 & 210,21 & 17,27 & 1361,89 & 377,04 & 27,69 \\
núcula & 194,30 & 23,73 & 12,21 & 257,29 & 52,02 & 20,22 & 272,94 & 54,26 & 19,88 \\
\hline
\end{tabular}

Os FC1 encontrados em cada mês de coleta de amostras de hortaliças estão dispostos na TABELA 2.

Observa-se que não existe influência dos meses de coleta e da safra sobre o FC1 nas hortaliças Alface Americana, Alface Lisa, Alface Crespa, Acelga, Agrião, Almeirão, Couve, Chicória, Espinafre, Mostarda, Repolho Branco, Repolho roxo, Rúcula. Tal fato permite que as UANs aperfeiçoem o treinamento dos colaboradores no intuito de diminuir, eliminar ou prevenir perdas. O fato de não ocorrer variação no FC contribui para que estas perdas sejam menores, ajudando a manter a padronização durante a manipulação chegando a um produto final de alta qualidade e baixo custo.

A sobrevivência das UANs depende, em grande parte, de processos de avaliação e mensuração das perdas ocorridas. Por isso técnicas para diagnosticar, avaliar e definir a relevância de processos e perdas diretas e indiretas devem ser desenvolvidas nas 
unidades. Tais técnicas servirão de subsídio para a realização de um eficiente e adequado planejamento.

TABELA 2 - EFEITO DOS MESES DE COLETA SOBRE O FC 1 DAS HORTALIÇAS COMERCIALIZADAS NO CEASA DE BRASÍLIA - DF, 2008

\begin{tabular}{lcccc}
\hline \multicolumn{1}{c}{ Hortaliças } & FC 1 abril & FC 1 maio & FC 1 junho & p-valor \\
\hline alface americana & $1,50 \mathrm{a}$ & $1,36 \mathrm{a}$ & $1,22 \mathrm{a}$ & 0,398 \\
alface roxa & $1,78 \mathrm{a}$ & $1,17 \mathrm{~b}$ & $1,25 \mathrm{~b}$ & $\mathbf{0 , 0 0 2}$ \\
alface lisa & $1,39 \mathrm{a}$ & $1,39 \mathrm{a}$ & $1,24 \mathrm{a}$ & 0,128 \\
alface crespa & $1,45 \mathrm{a}$ & $1,45 \mathrm{a}$ & $1,33 \mathrm{a}$ & 0,848 \\
acelga & $1,67 \mathrm{a}$ & $2,08 \mathrm{a}$ & $1,38 \mathrm{a}$ & 0,241 \\
agrião & $2,75 \mathrm{a}$ & $2,43 \mathrm{a}$ & $1,80 \mathrm{a}$ & 0,059 \\
almeirão & $1,57 \mathrm{a}$ & $1,79 \mathrm{a}$ & $1,50 \mathrm{a}$ & 0,846 \\
couve & $1,52 \mathrm{a}$ & $1,60 \mathrm{a}$ & $1,68 \mathrm{a}$ & 0,603 \\
chicória & $1,53 \mathrm{a}$ & $1,48 \mathrm{a}$ & $1,35 \mathrm{a}$ & 0,676 \\
espinafre & $1,59 \mathrm{a}$ & $1,43 \mathrm{a}$ & $1,70 \mathrm{a}$ & 0,102 \\
escarola & $1,36 \mathrm{a}$ & $1,44 \mathrm{a}$ & $1,04 \mathrm{~b}$ & $\mathbf{0 , 0 0 3}$ \\
mostarda & $1,69 \mathrm{a}$ & $2,11 \mathrm{a}$ & $1,46 \mathrm{a}$ & 0,356 \\
repolho branco & $1,12 \mathrm{a}$ & $1,12 \mathrm{a}$ & $1,12 \mathrm{a}$ & 0,996 \\
repolho roxo & $1,11 \mathrm{a}$ & $1,13 \mathrm{a}$ & $1,11 \mathrm{a}$ & 0,874 \\
rúcula & $2,07 \mathrm{a}$ & $1,71 \mathrm{a}$ & $1,79 \mathrm{a}$ & 0,408 \\
\hline
\end{tabular}

Nota: As médias com letras iguais não diferem estatisticamente ao teste de Tukey (pvalor $<0,05)$.

$\mathrm{Na}$ hortaliça Alface Roxa pode-se notar que o FC 1 do mês de maio e junho difere do FC 1 de abril. Já o FC 1 do mês de maio é estatisticamente igual ao FC 1 do mês junho, demonstrando que apesar da alface roxa ser uma hortaliça que possui um cultivo semelhante às outras alfaces, há, possível, a influência da safra.

$\mathrm{Na}$ hortaliça Escarola, verifica-se que o FC 1 do mês de abril e maio é diferente do FC 1 do mês de junho. Nos meses de maio e abril, o FC 1 é estatisticamente igual. Uma vez que a safra da hortaliça em questão compreende o mês de junho, é possível demonstrar claramente a influência da safra no produto comercializado.

Para sintetizar os resultados obtidos para o FC2, a TABELA 3 apresenta a média de cada mês para cada hortaliça.

\begin{tabular}{lcccc} 
TABELA $3-$ EFEITO DOS & MESES & DE COLETA & SOBRE O FC2 DAS & HORTALIÇAS \\
& COMERCIALIZADAS NO & CEASA DE BRASÍLIA - DF, 2008 & \\
\hline Hortaliças & FC 2 abril & FC 2 maio & FC 2 junho & p- valor \\
\hline acelga & $3,22 \mathrm{a}$ & $3,31 \mathrm{a}$ & $2,50 \mathrm{a}$ & 0,406 \\
agrião & $4,00 \mathrm{a}$ & $5,05 \mathrm{a}$ & $3,20 \mathrm{a}$ & 0,147 \\
espinafre & $1,97 \mathrm{a}$ & $1,96 \mathrm{a}$ & $2,21 \mathrm{a}$ & 0,608 \\
rúcula & $3,35 \mathrm{a}$ & $3,44 \mathrm{a}$ & $2,94 \mathrm{a}$ & 0,429 \\
\hline
\end{tabular}


Nota: As médias com letras iguais não diferem estatisticamente ao teste de Tukey (pvalor $<0,05)$.

Nenhuma das hortaliças sofreu influência dos meses de coleta e da safra sobre o FC2. No contexto apresentado é válido lembrar a influência do planejamento de cardápio sobre o FC2, pois nesta fase são retiradas as partes que são habitualmente consumidas, mas que em determinadas preparações não serão utilizadas. Um bom exemplo de reaproveitamento das hortaliças seria os talos do agrião para a produção de bolinhos, ou os talos de couve para a produção de farofas ou sucos o que agrega valor nutritivo às preparações. Devido ao exposto é necessário que haja treinamentos na UAN para que as perdas sejam aproveitadas de maneira que não influenciem o custo e o valor nutricional do cardápio.

Conforme a TABELA 4 é possível inferir que o FC 1 coletado da alface lisa é significativamente maior que o FC 1de Ornelas (2001) e menor que o FC1 de Luna. Para a alface crespa o FC 1 coletado é significativamente menor que o FC1 apresentado em Luna. Na acelga, o FC 1 coletado é estatisticamente igual ao FC 1 de Ornelas e significativamente maior que o FC1 de Luna (1999). No caso do agrião o FC 1 coletado é significativamente maior que o FC 1 de Ornelas (2001).

Para o almeirão o FC1 coletado é significativamente maior que o FC 1 Luna (1999), já para a couve e para o repolho roxo os FC1 coletados são estatisticamente iguais ao FC 1 Luna (1999). Para a chicória o FC1 coletado é estatisticamente igual aos FC 1 de Ornelas (2001) e de Luna (1999). Já para o espinafre o FC1 coletado é significativamente menor que o FC1 de Ornelas (2001) e significativamente maior que o FC1 de Luna (1999).

Os FC1 coletados da escarola e do repolho branco são significativamente menores que o FC1 Ornelas (2001) e de Luna (1999) e o FC 1 coletado da rúcula é significativamente maior que o FC 1 apresentado por Luna (1999).

TABELA 4 - COMPARAÇÃO ENTRE O FC 1 COLETADO E DA LITERATURA DE HORTALIÇAS COMERCIALIZADAS NO CEASA DE BRASÍLIA - DF, 2008

\begin{tabular}{lccccc}
\hline & Coletado & Ornellas & Luna & p-valor & p-valor \\
\multicolumn{1}{c}{ Hortaliças } & FC 1 & FC 1 & FC 1 & Ornellas & Luna \\
\hline alface lisa & 1,34 & 1,09 & 1,53 & 0,0000 & 0,0003 \\
alface crespa & 1,41 & - & 1,60 & - & 0,0225 \\
acelga & 1,71 & 1,54 & 1,07 & - & 0,0031
\end{tabular}




\begin{tabular}{lccccc} 
agrião & 2,33 & 1,78 & - & 0,0077 & \\
almeirão & 1,62 & - & 1,12 & - & 0,0025 \\
couve & 1,60 & - & 1,68 & - & 0,1134 \\
chicória & 1,45 & 1,40 & 1,31 & 0,2571 & 0,0510 \\
espinafre & 1,57 & 1,78 & 1,11 & 0,0023 & 0,0119 \\
escarola & 1,28 & 1,92 & 1,50 & 0,0054 & 0,0053 \\
repolho branco & 1,12 & 1,72 & 1,23 & 0,0000 & 0,0095 \\
repolho roxo & 1,12 & - & 1,11 & - & 0,2972 \\
rúcula & 1,86 & - & 1,57 & - & 0,0147 \\
\hline
\end{tabular}

De acordo com a tabela 5, o FC 2 coletado da acelga é significativamente maior que o FC 2 de Ornelas (2001) e o FC 2 coletado do espinafre é significativamente maior que o FC 2 de Luna (1999).

TABELA 5 - COMPARAÇÃO ENTRE O FC 2 COLETADO E DA LITERATURA DAS HORTALIÇAS COMERCIALIZADAS NO CEASA DE BRASÍLIA - DF, 2008

\begin{tabular}{lccccc}
\hline & Coletado & Ornellas & Luna & p- valor & p- valor \\
Hortaliças & FC 2 & FC 2 & FC 2 & Ornellas & Luna \\
\hline acelga & 3,01 & 1,66 & - & 0,0003 & - \\
espinafre & 2,05 & - & 1,81 & - & 0,0029 \\
\hline
\end{tabular}

Ao analisar os dados percebe-se que os autores Ornelas (2001) e Luna (1999) não descrevem a técnica utilizada no pré-preparo, a habilidade da mão-de-obra, sazonalidade do produto e qualidade do produto, que são fatores que influenciam diretamente o FC. Dessa forma a comparação dos fatores é dificultado, devido a não padronização/informação das técnicas de coleta e manipulação das hortaliças. Para o FC1 encontrou-se 26\% de adequação com a literatura e para o FC 2 os valores coletados diferiram da literatura em sua totalidade.

\section{CONCLUSÃO}

Conclui-se então que a diferença dos resultados apresentados neste estudo em relação aos dos autores citados, se dá em parte, pela ausência de informações em suas pesquisas quanto aos critérios utilizados, tais como manipulação, safra, e partes retiradas das hortaliças.

Ao analisar as diferenças do FC, tamanho do produto entre os fornecedores foi percebido o quanto este é diretamente proporcional ao tempo decorrido após a colheita e 
a oferta, ou seja, quanto mais atual a colheita, quanto maior for a padronização do fornecedor, quanto mais adequado for o transporte e armazenamento mais íntegro o alimento e, conseqüentemente, menor a perda e o desperdício por partes amassadas, machucadas, estragadas e impróprias para o consumo. Assim, pode-se concluir que medidas tomadas desde a pós-colheita até o comensal são necessárias. Ainda podemos afirmar que cada UAN, deve construir sua tabela de FC, pois este é um indicador de desperdício que pode ser influenciado pelos critérios citados acima e cada UAN possui suas características internas.

Para a excelência do processo de produção é necessário que se compreenda a utilização correta de técnicas como limpar, descascar, picar e selecionar, entre outros procedimentos que representam uma perda inevitável dos insumos utilizados. Sua otimização deve levar em conta critérios econômicos. Por exemplo, deve-se tentar aproveitar ao máximo os alimentos em relação às cascas, talos, partes folhosas removidos, quando possível, aproveitar para outros fins, subdividindo-os ou mesmo utilizando-os em outras preparações.

Também para otimizar a produção e diminuir os gastos da UAN, os equipamentos mecânicos adequados devem ser utilizados no processamento, estes são mais empregados para descascar hortaliças, exigindo um retoque manual para que o trabalho se complete. O emprego de maquinários especializados no pré-preparo dos alimentos define a diminuição de suas perdas, e deve justificar-se economicamente.

A manutenção da qualidade de consumo de um produto alimentício in natura não depende unicamente do meio ambiente, do uso de máquinas, de métodos e de matérias-primas adequadas. O ser humano é o elemento central na implantação de sistemas de qualidade em qualquer organização. Desta maneira, todos os indivíduos que compõem a organização e o processamento das hortaliças precisam ser conscientizados das especificidades e cuidados que tais alimentos exigem.

\section{REFERÊNCIAS}

ARAújo, W. M. C.; MOntebello, N. P.; Botelho, R. B. A. Alquimia dos alimentos. Brasília: Senac, 2007. 
AKUTSU R.C.; BOTELHO R. A., CAMARGO E. B., SÁVIO K. E. O., ARAÚJO WC. Adequação das boas práticas de fabricação em serviços de alimentação. Revista Nutrição. 2005; 18(3):419-27.. Campinas,v.18, n. 3, p. 419-427, Maio/ Jun. 2005.

BORGES, R. F. Panela Furada: o incrível desperdício de alimentos no Brasil. São Paulo: Columbus, 1991.

Botelho, R.A; CAMARGo, E. B. Técnica dietética - Seleção e Preparo de Alimentos - Manual de Laboratório. 01. ed. São Paulo: Atheneu, 2005. v. 1. 167p.

BRASIL. Ministério da Saúde. Agência Nacional Vigilância Sanitária. Resolução Comissão Nacional de Normas e Padrões para Alimentos no 12, de 24 de julho de 1978. Disponível em: <http://www.anvisa.gov.br/legis/resol/12_78.pdf>. Acesso em: 20 jun. 2008 .

BRASIL. Ministério Da Agricultura, Do Abastecimento e da Reforma Agrária. Relatório preliminar da Comissão Técnica para redução das perdas na Agropecuária. Brasília: MAARA, 1993. 78 p.

BRASIL. Ministério da Agricultura, Pecuária e Abastecimento. Companhia de Entrepostos e Armazéns Gerais de São Paulo. Diga não ao Desperdício. Disponível em: <http://www.ceagesp.com.br>. Acesso em: 20 jun. de 2008.

EVANGELISTA, J. Alimentos: um estudo abrangente. Rio de Janeiro/ São Paulo. 1992, Atheneu. 450 p.

GOMES, F. P. Curso de estatística experimental. 14 ed. Piracicaba. Degaspari, 2000. $477 \mathrm{p}$.

GOMES.J. S.; SALAS, J. M. Controle de Gestão - uma abordagem contextual e organizacional. São Paulo: Atlas, 1997.

GUIMARÃES, F. P. M.; SOUZA, G. Importância do receituário padrão em Fast Service. Revista Nutrição em Pauta, v.20, 2000.

HIRSCHBRUCH, M. D. Unidades de Alimentação e Nutrição: desperdício de alimentos x qualidade da produção. Higiene Alimentar, v. 12, v. 55, p.12-14, 1998. 
IEA- Instituto de Economia Agrícola. O papel da logística na cadeia de produção dos hortifrutis. 2005. Disponível em: http://www.iea.sp.gov.br/out/verTexto.php? codTexto $=2160$

LANZILlOTTI, H. S.; MONTE, C. R.V.; COSTA, V. S. R.; COUTO, S. R. M. Aplicação de um modelo para avaliar projetos de unidades de alimentação e nutrição. Nutrição Brasil, v. 3, n. 1, p. 11-17, 2004.

LUNA, N. M. M.; TEIXEIRA. A. B. Técnica Dietética Fator de Correção em Alimentos de Origem Animal e Vegetal. Cuiabá, 2 ed., 1999.

ORNELAS, L.H. Técnica dietética: seleção e preparo de alimentos. 7. ed. São Paulo: Atheneu, 2001. 296p.

PANETA, J. C. Qualidade na matéria-prima. Cozinha Industrial, ano IV, nº 21,1992.

PEREIRA,G. S.; CASTRO, I. R. Considerações sobre o plano de combate à fome e a miséria. Caderno Saúde Pública. 1993;9 (Sup. 1):106-13.

PERONE, M. País do desperdício. 2004. Disponível em: < http://redeglobo.globo.com/ cgibin/jornaldaglobo/montar_texto.pl?controle=2963

PRODUÇÃO INTEGRADA DE FRUTAS (PIF). Frutas e hortaliças: fonte de prazer e saúde. São Paulo: PIF Logística Pós-colheita, 2006. 06 p.

PROENÇA, R. P. C.; SOUSA, A. A.; VIEIROS, M. B.; HERING, B. Qualidade nutricional e sensorial na produção de refeições. Nutrição em Pauta, Campinas, v. 13, n. 75, p. 4-16, nov./dez. 2005.

TEICHMANN, Ivone M. Tecnologia culinária. Caxias do Sul: EDUCS, 2000. 